\title{
The Value of Incorporating Indigenous Games in the Teaching of Number Sentences and Geometric Patterns
}

\author{
S.A. Tachie ${ }^{1}$, B.F. Galawe ${ }^{2}$ \\ North-West University ${ }^{1}$, University of the Free State ${ }^{2}$ \\ South Africa
}

\begin{abstract}
The purpose of this study was to investigate the incorporation of indigenous games into mathematics classrooms to assist teachers in the teaching and learning of number sentences and geometric patterns in the Motheo Education District of the Free State, South Africa. The literature analysis looked at the existing knowledge, based on the use of indigenous games in mathematics classrooms, to assist teachers in the teaching of number sentences and geometric patterns. The performance of learners in mathematics is influenced by various factors. In particular, one of the significant factors that the current study identified, was the lack of knowledge that teachers themselves had about indigenous games, especially in rural schools. The researchers utilised a contextual, qualitative method with a phenomenological approach to meet the objectives of the study. Two Intermediate Phase teachers were purposively selected to take part in this study. Observation and interviews were used for data collection and content analysis technique was then used to analyse the data gathered. The findings of the study revealed that the participant teachers were initially not aware of the value of using indigenous games in the teaching of number sentences and geometric patterns. The methods that were being used by the teachers in the teaching of these mathematical concepts were teacher-centred rather than learner-centred which meant that learners struggled to understand simple concepts. The traditional practices such as the chalk-and-talk method' were still being embraced in the mathematics classroom to teach number sentences and geometric patterns. The prior knowledge of learners was also seldom prioritised and impeded the performance of learners. Furthermore, the study revealed that, when the participants were informed of the purpose of the indigenous games in relation to teaching and learning, they enjoyed the use of them (indigenous games) such as morabaraba, which effectively helped them in the teaching of number sentences and geometric patterns to Grade 4. Recommendations were made concerning the above findings, particularly regarding further investigation.
\end{abstract}

Keywords: Indigenous games, number sentences, geometric patterns, mathematics, morabaraba and Grade 4.

\section{Introduction}

The purpose of this study was to advocate for the incorporation of indigenous games into mathematics classrooms and to assist teachers teaching Grade 4 learners on the methods to use in the teaching of number sentences and geometric pattern using morabaraba. Morabaraba, an indigenous game played by children in parts of South Africa and Botswana, is a board game and its name is derived from the Southern Sotho words 'moraba and raba' which means to mill or go round in circles. Education in South Africa is largely based on foreign ethics and values [1] and the manner in which the education system is structured, more often than not, uses foreign ideologies more than indigenous ones [2]. South Africa's Curriculum Policy Statement [3], aims at valuing indigenous knowledge in the teaching and learning of mathematics, especially in the Foundation Phase. However, foreign ethics and values, being overused in the South African education system, has silenced the use of indigenous games [4] as a tool or strategy that could assist mathematics teachers in the teaching and learning of number sentences and geometric patterns. The use of foreign ethics and values has disadvantaged South African learners in understanding basic concepts in mathematics, especially for number sentences and geometric patterns, and has affected the performance of learners in mathematics in the country [5]. According to Maree and Van der Walt [6], the high failure rate amongst many South African learners could be due to the fact that a large percentage of teachers in the schools do not implement the use of indigenous games in their teaching. It is believed that the adaptation of a foreign culture has affected South Africans on several levels, including that of the economy. Molefe [7] states that indigenous games impact on a number of socio-economic issues in the lives of South Africans, such as African identity, cultural diversity, education and training, accessibility to resources, international relations and economic growth. Learners cannot apply the 
teaching methods currently being used in our schools since they do not relate to their daily activities, especially those learners from disadvantaged backgrounds.

It was further established that the use of such skills and materials, as mentioned above, promotes spontaneous interaction amongst learners as they communicate during activities with their peers $[8,9]$. According to Mudaly [4], indigenous games, for example, the use of the Zulu kraal, as well as the cattle kraal, supports the teaching and learning of mathematics when concepts such as parabola is incorporated into teaching and learning in schools. This helps to raise the learners' interest and motivation in the learning of mathematics. The enjoyment of these games was not restricted to a specific cultural group, but was also enjoyed in a multicultural setting. According to DinanThompson et al. [10], much of Africa's rich history of indigenous games has become extinct without having been documented in historical and anthropological accounts of the indigenous people of Africa. This has gradually silenced the use of indigenous games in the teaching and learning of mathematics in the current generation in schools, especially in the Motheo Education District of the Free State Province of South Africa. There is, therefore, a need to incorporate indigenous games such as morabaraba in the teaching and learning of number sentences and geometric patterns. The researchers therefore believe this concept will assist and motivate learners in the learning of mathematics, leading to a reduction in the failure rate of South Africa learners.

The Department of Sport and Recreation actively promotes indigenous and even formal games for use in South Africa's education system. Various indigenous games, such as dibeke (a running ball game), diketo (a coordination game), kgati (a rope jumping game); morabaraba (a board game) and drie stokkies (a running and jumping game) have been identified as benefitting learners in their learning and understanding of mathematics. Incorporating indigenous games requires physical activity, social skills, creativity, imagination and most importantly, traditional children's games stimulate growth, both physically and intellectually. There are several benefits in using traditional indigenous games to boost education, such as bringing together indigenous and non-indigenous people and providing essential training in social interaction [11]. Looking at the way indigenous games can support teaching and learning in South African schools, it is incumbent on the current researchers to see how these games can be incorporated into the teaching of mathematics in the 21 st century, hence the current study. The use of indigenous games, in general, provides the learners with an opportunity to relate to their experiences outside the classroom with regard to the mathematical concepts and processes encountered in their mathematics classroom. This, to a greater extent, creates a familiarity between mathematics and indigenous games and, in the process, helps learners to overcome their fear of mathematics. Related literature has shown that learners' failure rate in mathematics in the country is related to many factors [12], which are influenced by both external and internal factors, such as teaching materials, classroom management, teacher knowledge and lack of motivation among learners, together with their negative attitude towards the subject.

It was further established that learners who have made use of indigenous games in learning certain mathematical concepts, developed a positive attitude towards the subject. According to Molefe [7], indigenous games impact on a number of socioeconomic issues in the lives of people, such as African identity, cultural diversity, education and training, accessibility to resources, international relations and economic growth. Despite the fact that the use of indigenous games does have a positive impact on a learner's performance, very little research has been conducted in this area, hence the researchers' decision to conduct this study.

\section{Problem Statement}

Related literature has indicated that the failure rate of learners in mathematics in the country is related to many factors [12]. In an attempt to address issues of poor performance, the Department of Basic Education (DBE) [3] has incorporated the use of indigenous games in the teaching and learning of mathematics, but the researchers have noted that teachers rarely incorporate these games in their teaching and learning of mathematics, as advised in the CAPS document. This seems to be a problem for many learners, as noticed during the observations conducted in some schools, as well as workshops which the researchers have conducted. They have noticed that learners find it difficult to understand some of the mathematical concepts without any physical objects being used for demonstration purposes or the incorporation of indigenous games. To the best of their knowledge, very little research has been conducted in this area, the Motheo Education District, hence the researchers' decision to investigate the given issue.

\section{Research Questions}

The following research questions were posed:

1. What teaching strategies are teachers currently using to assist learner understanding when teaching Grade 4 number sentences and geometric patterns?

2. How does the use of morabaraba support learner understanding of number sentences and geometric patterns? 


\section{Theoretical Framework}

The understanding of number sentences and geometric patterns requires a great deal of basic knowledge on the part of the learner, as well as the use of relevant teaching materials and manipulatives, that will help to portray the meaning and facilitate understanding of the concepts. For teachers to embrace indigenous games such as morabaraba as a useful tool in their teaching and learning of number sentences and geometric patterns, they need to engage in constructive dialogue or discourse to indicate the potential and value of the game when used in the teaching and learning of number sentences and geometric patterns. This requires a relevant theory that both welcomes and encourages teacher discussion, as well as learner input in a classroom situation.

The study was informed by socio-cultural theory. Studies have shown that socio-constructivist theory allows learners to construct knowledge from their indigenous perspectives, which improves their learning skills [13]. Constructivism is a theory based on the observation and scientific study of how people learn [14]. People construct their own understanding and knowledge of the world through experiencing things and reflecting on them. Utilising indigenous knowledge and skills such as the game of morabaraba is supported by socio-constructivist theory, and facilitates the teaching of number sentences and geometric patterns. Teachers can establish the effective use of morabaraba in their teaching and, learning through this study, to change what we believe to be irrelevant and to embrace what is known to be relevant. Research has shown that when we encounter something new in our environment through teaching and learning, we have to reconcile it with our previous ideas, and experience its uses for the benefit of future development [15]. Hence the use of morabaraba to improve the teaching and learning of number sentences and geometric patterns. In South African classrooms, the constructivist view of learning points towards a number of different teaching practices which are considered to be efficient tools in teaching and learning [16]. In the most general sense, it usually means encouraging learners to use active techniques to create wider knowledge and to then reflect upon, to talk about what they are doing and how their understanding is changing. This gives teachers the chance to encourage learners to constantly assess how the activity helps them gain understanding. In this study, teachers needed to engage themselves in constructive discourse to establish how the use of morabaraba would assist in the teaching and learning of number sentences and geometric patterns, hence the use of this theory.

Research support for constructivist teaching techniques has been mixed, with some supporting these techniques and others contradicting. For this reason, the teaching and learning methodologies should adapt to incorporate scaffolding whereby teachers consult and build on the prior knowledge of learners before introducing new concepts [14]. The relationship of the teacher and learner is essential for an effective learning and teaching process. Teachers need to be aware of the learner experiences, barriers to their learners to ensure that real life experiences are incorporated in teaching and learning. It is therefore be important for learners to be exposed to learning opportunities that link mathematical concepts with authentic learning situations. The nature of mathematic revolves around rules which is reflected in the game of morabaraba; in order to achieve an outcome, certain procedures must be followed.

In the game of morabaraba, players need to follow the instructions of the game, which is played on a special board with 24 cells connected with lines. There are two players or two teams with a number of players. Each player has 12 men and the object of the game is to capture at least 10 opponent's men or to block all opponent's men completely. Each player wishes to win the game while simultaneously following the rules and working through the three stages of the game in firstly placing the men, then moving the men and finally, flying the men. This is in line with mathematical problem solving, as certain rules have to be followed in solving a mathematical problem. Players plan their moves and strategies, while keeping all the rules in mind. Utilising the game of morabaraba in the teaching of number sentences and geometric patterns is the primary aim of this research in an attempt to embrace the culture of incorporating indigenous games and enhancing the quality of teaching.

\section{Literature Review}

\subsection{Teaching Approaches Currently used by Teachers in the Teaching of Mathematics}

Knowledge of mathematics is essential for all members of our society. To participate fully in our democratic society and to be unrestricted in career choice and advancement, people must be able to understand and apply mathematics ideas in everyday life. South Africa, like any other developing country, is faced with the problem of a critical shortage of professionals like engineers, medical doctors and other scientifically-oriented professionals [17]. Competence in mathematics is essential for the production of such professionals later in life. There are very few qualified Black South Africans at present, in these professions and even in mathematics teaching which underpins these professions.

Studies have shown that outdated teaching practices and lack of basic content knowledge 
associated with teachers' methods of teaching have resulted in poor teaching standards in mathematics $[17,18]$. The poor standards have also been exacerbated by a large number of underqualified and unqualified teachers who are faced with teaching in an overcrowded environment not conducive to teaching and learning. Further studies conducted by the educational researchers $[17 ; 19]$ have identified various reasons for the cause of incompetency among teachers as well as poor performance in mathematics. Amongst these are outdated teaching practices, teachers' lack of basic content knowledge, underqualified or unqualified teachers, overcrowded and poorly equipped classrooms, inefficient teaching approaches and unprofessional attitudes $[18,20]$. Further to this are teachers' inability to help learners develop their own thinking, enhance metacognitive strategies and become problem solvers [6,21]. Related studies such as Mevarech and Kramarski [22] investigating challenges faced by teachers in South Africa and many other countries with developing economies, refers to the lack of teachers' mathematical content knowledge. Outdated teaching practices and lack of basic content knowledge have resulted in poor teaching standards as well as learners' poor performance in mathematics. This pattern has alarmed many scholars such as Markey, Power and Booker [23], Moloi [24], Nabie and Sofo [25], Nkopodi and Mosimege [9] who have conducted research on the use of indigenous games in developing mathematical concepts which ensures learners' freedom of learning. Their findings are supported by Nabie and Sofo [25] who indicated that personal mathematical construction of learners' own learning and mathematics learning is supported by the use of games in mathematics education.

According to Grane [26], the problem of poor performance of learners is not confined to languages only, as experienced in South African schools, but is also prevalent in other subjects as well. According to Gardner [27], "the flattery or detailed compliment of this assertion is essentially demonstrated by the number of learners who are poor mathematicians, and not only poor mathematicians, but poor in other related school subject skills". Different socioeconomic factors, lack of basic mathematics skills and lack of resources influence the performance of learners in mathematics [28].

A research document developed by the National Research Council [29] addresses the learning process. The purpose of this report was to discuss teaching methods which could be used to improve the learning of mathematics so that learners are proficient. Teaching of number sentences and geometric patterns can be taught both with a formal or informal approach. The most commonly used method is chalk-and-talk method which tends to be a monologue presentation done with the teacher illustrating the content by drawing with chalk, hard crayon, or pastel, or with dry-erase markers on a blackboard, traditionally, or a whiteboard. The chalk-and-talk method of teaching focuses on the blackboard and the voice and the physical activity of the teacher. This method is preferred for presenting lectures and talks. The lecture method is based on the philosophy of idealism and refers to the explanation of the topic to the students. According to Renzulli [30] the teacher clarifies the content matter to the students by using gestures, simple devices, by a change in voice, change in position and facial expressions. In this teaching method, teachers are more active and learners are passive but the teacher also asks questions to keep the learners attentive.

The flipped classroom, defined by Zainuddin and Halili [31] as an instructional strategy and a type of blended learning, reverses the traditional learning environment by delivering instructional content, often online, outside of the classroom. The flipped classroom has been incorporated as a teaching approach as it moves activities, including those that may have traditionally been considered as something done at home, into the classroom and focuses on learner engagement, the use of technology and the opportunity to create meaningful learning opportunities where topics are explored in greater depth. The flipped classroom allows learners to watch online lectures, collaborate in online discussions, or carry out research at home while engaging in concepts in the classroom with the guidance of a mentor.

Mphuthi [32] suggests that geometry can be taught in an informal way with cutting and folding incorporating practical methods to make learning more meaningful. This method is interconnected with the discovery method which is defined as a process that involves problem solving situations where the learners draws on their own experiences and prior knowledge and where learners interact with their environment by exploring and manipulating objects, wrestling with questions and controversies. Aligned with the flipped classroom is the game-based learning approach, defined as an approach that involves innovative and creative apps that are based on computer games that possess educational benefits. This type of learning according to Chien, $\mathrm{Wu}$ and Hsu [33] support learning and teaching enhancement, assessment and evaluation of learners.

\subsection{The use of Indigenous Games such as Morabaraba and Others, in the Teaching of Number Sentences and Geometric Patterns}

Smith [34] argues that "good teaching is understood to involve a process of facilitating learning rather than being the simple transmission of knowledge from the educator to the learner". The teachers' role is to facilitate learning using a variety 
of approaches and methods to ensure that the diverse needs of learners are addressed and that all learning styles are taken into account. This means that flexible teaching approaches should be used by teachers in order to address the different learning styles of the learners, as supported by the NCTM [28] and the lesson needs to be presented according to the learners' preferred learning style.

Copur-Gencturk [35] suggests that understanding the definition of the concept being taught plays an essential role in teaching and learning. For example, if the educator is teaching the concept of the various functions, there should be a clear definition of the concept and the types of functions. These should be well explained to the learners during the introductory stage of the lesson. Teachers should encourage a "hands-on" and interactive approach to learning with activities offering learners the opportunity to apply and interact equally with the thinking and performing aspects of learning. Learners should be given the opportunity to collaborate, reason, discuss and negotiate during problem-solving.

Teachers should regard learners as co-producers of new knowledge and skills but need to take into account prior knowledge of learner for learning to be effective [36]. This would assist the teachers in scaffolding the learners and assist them in achieving the learning outcomes. However, the learners should not be viewed as passive recipients of information and empty vessels to be filled with good information by the teachers. The shift from an "instructivist" to a 'constructivist' approach should be adopted by the teachers of mathematics and other subjects. The quality of instruction, which includes using strategies like effective questioning and continuous assessment, would thus be enhanced.

In order for learners to learn effectively and achieve learning outcomes, teachers often need to change or adapt the teaching/learning methods particularly when learners do not understand the work clearly during lesson delivery. The learning environment should create a connection between real-life situations and mathematical concepts taking into account the visual, the theoretical as well as the logical. Authentic learning is prominent in teaching geometry, as reflected in current school curricula [37]. The teaching of number sentences and geometric patterns could also use indigenous games like morabaraba. Moloi [24] used morabaraba, a board game, to teach mathematics for better understanding. As previously explained, morabaraba is the board game played by two people, with 24 tokens with 12 for each player. The aim of the game is to create rows of three cows (tokens), being vertical, diagonal or horizontal. The following mathematical concepts: area, ratio, proportions, geometric figures, numerical patterns and similarity are addressed in the playing of this game. Mathematical skills targeted include logic, reasoning, construction, accuracy on calculations, interpretation and identifications [38].

Many indigenous games can be used in the mathematics classroom. For example, a game called arauru or pada, where a child balances on one foot and uses it to push a stone from one drawn rectangular box to the other, can be used in the teaching of the concepts of balancing and counting. When playing the game, the player scores more by balancing on one foot without resorting to using the other foot and pushing the stone across squares drawn on the ground. In order to balance on one foot, one has to strategically position oneself on that foot. Learners also learn to count in the process because one has to remember whether she/he will start from which box. A see-saw using a plank can also be used to teach balance, mass and weight [38].

According to Mbusi [39], the use of isiXhosa dance can be used to explain geometry concepts such as right angles. A study conducted by Hunter et al. [40] revealed the teaching of mathematics using kinaesthetics or musical ways. In a similar manner, Muller et al. [41] used the gumboot dance linking it to mathematical concepts. Which makes it evident is that culture, language and geographical spaces have a continuous impact of mathematical development Almond and Verba [42] as well as Owens [43] stated that games are activities with integrated opportunities, a statement supported by Nabie et al. [44]. Therefore, this means mathematics teachers, especially those in rural schools, need to be trained and exposed to the concept of ethno-mathematics by incorporating indigenous knowledge systems in the teaching of complex mathematics topics.

\section{Methodology}

The research, which was conducted in the Motheo district of the Free State province of South Africa, is a qualitative study that used a phenomenological approach and the interpretation of raw data obtained from the participants [45]. In this study, two Intermediate Phase teachers were purposively selected from two schools and the schools were purposively selected based on a cluster sampling technique. The selected teachers had a minimum of five years' teaching experience, during which time, they should have acquired sound subject matter knowledge in the teaching of mathematics. Two instruments were used for data collection, namely observation and interviews. During the observation, both teachers were observed as they presented their lessons. Unstructured and openended interviews were also conducted with the two teachers thereafter, which were recorded and later transcribed and analysed. 


\section{Data Analysis}

Qualitative analysis involves three elements which are arranging data, breaking it into manageable units, synthesising and searching for patterns. This is process used by the researcher to develop theories from the information gathered through interviews, observation, and documents analysis. The gathering of information involves the selection of data, techniques of data collection and the transcription through note taken [58]. In this study, content analysis was used for data analysis. Content analysis is defined as a process that involves observation, verbatim transcriptions, and responses from the open-ended questions as well as video recordings obtained from the participants of any study for credible data [47]. Therefore, in this study the data analysed included notes taken during observation of the lessons presented by the participants as well as open-ended interviews conducted with participants to generate better outcome considering the purpose of the study. Firstly, the researchers transcribed the interview data verbatim, read and reread through the data over and over again until they were familiar with the content. They then used the explicit rules of coding to code chunks of text which were them arranged in content categories and later into themes and subthemes.

The researchers examined the data in-depth which provided detailed descriptions in an attempt to answer the research questions. The analysis of the participants' responses to each question is presented in the subsection below and begins by offering an outline of the biographical information of participants.

\subsection{Biographical Information of the Participants}

A total of two teachers were invited to participate in the study. For an in-depth analysis, it is important to present a brief overview of the biographic characteristics of the participants, which include their age, sex of respondents, years of teaching experience, highest qualification, position held and type of school. This is presented in Table 1 below.

Table 1. Biographical information

\begin{tabular}{|l|c|c|c|c|c|c|}
\hline Participants & Age & Sex & $\begin{array}{c}\text { Teaching } \\
\text { Exp. }\end{array}$ & $\begin{array}{c}\text { Highest } \\
\text { Qualification }\end{array}$ & $\begin{array}{c}\text { Position } \\
\text { held }\end{array}$ & Type of school \\
\hline Teacher (TA) & 54 & F & 9 years & B.Ed. & Teacher & Public \\
\hline Teacher (TB) & 49 & M & 25 years & B.Ed. & HOD & Public \\
\hline
\end{tabular}

It is evident from Table 1 that the two teachers who participated in the study were qualified teachers with a Bachelor degree in Education. One participant is a Head of Department (HOD) (post level two educator) and the other is post level 1. Both work in the selected public schools in a rural area.

\subsection{Data Presentation}

7.1.1. Classroom observation. The researcher observed the teachers in the teaching of mathematics lessons and the observations are presented below: Both teachers used the chalkboard to capture information but they applied it differently. For instance, Teacher A would more often write only correct answers on the board. Teacher B would explain both the correct and incorrect answers given by learners on the board, and then encourage learners to correct their mistakes. In most cases, he encouraged learners in constructive discussion about their views based on the problem at hand before pronouncing the correct answer.

Teacher A used a traditional approach of teaching whereby he would often give learners explanations rather than supporting learners to make sense of the information or problem given. On the other hand,
Teacher B gave learners homework once a week after he realised that most learners were struggling to apply their knowledge and therefore made use of indigenous games to express some concepts to the learners for better understanding. The extract from the teachers' interviews substantiated the above statement.

Teacher A: I usually provide answers for learners where they face problems by making use of indigenous games by guiding them to apply its use. Teacher B: As for me, I allow or force learners to deliberate on their answers and further ask them to draw conclusion for themselves under my supervision and later show the correct answers through discussions.

The researcher observed some teacher-learner interaction during the teaching and learning process. It seems that both teachers interacted with learners for purpose of maintaining learners' interest and developing understanding of a particular concepts or topic. The practice helped the teachers identify learners that were struggling when doing corrections.

7.1.2. Interviews with participant teachers. In this section, responses given by teachers during the 
interviews are presented with some discussion as demonstrated below.

Question 1(a): Name at least 3 major barriers or challenges that you have encountered in mathematics classes.

Based on this particular question, all the participants, drawing on their experience, responded by stating factors that they classify as barriers to the learning and teaching of number sentence and geometric patterns. The participants listed the inability of learners to use local objects for learning mathematics as a barrier to the learning and teaching of number sentences and geometric patterns, as based on their experiences. These two participants highlighted the following as the challenges faced by learners in their classrooms.

Teacher A: Learners struggle to understand some of the mathematical concepts introduced by their teachers, especially when the teacher has a maths phobia but is teaching the subject due to redeployment. For example, learners struggle to understand concepts such as ascending and descending order, especially where their teachers failed to use practical examples to explain the concept.

Teacher B: Number sentences and geometric patterns are difficult for learners. Learners had difficulty in understanding these mathematical concepts.

Question 1(b): To what extent have you assisted or in what ways do you assist learners with the barriers or challenges mentioned above?

Teachers stated that they usually utilised different activities and non-traditional methods to help learners overcome their challenges. In addition, they provided extra classes to assist learners. The excerpt below from the teachers supports the above statement:

Teacher A: I usually write the definitions for learners on the board; thereafter I explain the terms used. I usually use teaching aids in the classroom, particularly when presenting shapes and spaces.

Teacher B: I always conduct extra classes for learners that are struggling to solving mathematical word problems especially in number sense and geometry patterns. During those extra classes, I use indigenous materials that are user friendly during my teaching to help learners understand the mathematical concepts being taught. This gives the learners the opportunity to showcase their talents in learning process.

Question 2 (a): What were the measures that you employed when you noticed that learners were struggling with geometric patterns and number sentences?
The two respondents claimed that though they used chalk-and-talk methods, they also made use of examples, as well as indigenous games to assist the learners in Grade 4 to understand number sentences and geometric patterns. For example, the teachers indicated that they used games like "chess", indigenous games and gave extra classes. The following excerpt supports this statement.

Teacher A: I conducted a lot of activities that relate to number sentences and geometric patterns by making use of various books and I sometimes used chess.

Teacher B: I normally use play games that are available to learners and play daily in my environment to explain certain concepts in number sense and geometry. This has been very fruitful to my learners to understand some basic concepts in mathematics and I will urge my colleagues to do same when teaching.

Question 3 (a): Do you incorporate the prior knowledge of learners when preparing your lesson plan?

Both teachers confirmed that they made use of learners' prior knowledge in order to make teaching effective. This is what they had to say:

Teacher A: Yes, I incorporate it because it is very important to know their background.

Teacher B: Yes. I try to consider what the learners know about the concepts before I present them.

Question 3 (b): Please share briefly how you would normally approach a new or challenging concept to make sure you teach it effectively.

The teachers indicated that they used practical activities in their classrooms. Teacher A indicated that she used teaching aids in the mathematics classroom. The excerpt below explains the views of both teachers:

Teacher A: I use teaching aids to guide my learners in learning some concepts in number sentences and geometric patterns.

However, Teacher B ensured that she was wellprepared and had discussed methods and approaches with other teachers to find the most appropriate ways of introducing a new or difficult concept.

Teacher B: I gather as much information as possible from other mathematics teachers before presenting it to the class.

Question 3(c): Can you share with me the teaching methods you use when teaching number sentences and geometric patterns.

The teaching strategies applied by teachers in the teaching and learning of number sentences and geometric patterns involved the traditional approach of teaching, whereby teachers do not use practical 
activities to develop the understanding of the learners. The excerpt below further supports the statement.

Teacher A: In most cases, I use chalk-and-talk... in the, flipped classroom to make my teaching and learning more interesting and understandable to learners.

Teacher B: In most cases, I use learner-centred approach through the use of technology.

Question 3 (d): What is your opinion concerning the use of a 'game approach' in mathematics when teaching number sentences and geometric patterns?

As the teachers had not incorporated the use of games in the teaching of number sentences and geometric patterns, they were later given information about the use of games in the teaching and learning in mathematics. They were asked for their response to this approach:

Teacher B: It is very good as it helps the learners to do maths on their own and also for learners to learn from one another. It helps a teacher to be able to plan their lessons for the learners according to their levels. It also helps stronger learners to explore information by themselves and to help weaker learners who are struggling.

Teacher A: The game approach in teaching and learning of geometric patterns and number sentences is a good idea mainly because learners will play attention to mathematics concepts in the game since learners like games.

Question 4 (a): Can number sentences and geometric patterns relate to real-life situations?

The teachers did not seem familiar with relating the teaching of mathematics to authentic learning. The excerpt below gives us a better understanding of the views of the teachers.

Teacher A: Yes, because in a real-life situation, such as washing their laundry, it involves measurement.

One of the participants mentioned that he used chess in his classroom. However, both teachers could not think of any number sentence and geometric pattern concepts applicable to the game. Teacher B: Yes, I always use chess.

Question 4(c): Can learners learn any mathematical concepts using morabaraba?

The curriculum encourages teachers to use indigenous games in their teaching and learning. However, teachers were not well informed about indigenous games such as morabaraba. Participant $\mathrm{B}$ indicated that he/she was not sure of the use of morabaraba. The excerpt below reflects their view: Teacher A: Yes, addition.
Teacher B: Not sure.

\section{Discussion of Findings}

\subsection{Barriers and Challenges faced by Teachers when Teaching Number Sentences and Geometric Patterns}

The study revealed that a lack of mathematical content knowledge possessed by teachers contributes highly to the poor performance of learners. Teachers are not trained to develop teaching strategies suitable for the effective teaching of number sentences and geometric patterns. Teaching practices and the lack of basic content knowledge have resulted in poor teaching standards, as well as learners' poor performance in mathematics in the country. The study further revealed that the curriculum is based on foreign ideology, rather than on local ones, a notion supported by Deresky [1], who mentioned that education in South Africa is based on foreign ethics and values which learners find difficult to understand.

\subsection{Methods currently used by Teachers in Teaching Mathematics in General}

The study revealed there are various teaching methods that can be applied when teaching number sentences and geometric patterns. For example, the chalk-and-talk method is teacher-centred and focuses the use of the voice and blackboard which does not allow for the use of formal or informal activities in the classroom. In using a 'flipped' classroom, the teacher taps into technology and makes use of learning materials which allow for authentic learning. Learners may watch online lectures and presentations or demonstrations and it grants learners the opportunity to learn in their own time and manner and for the teacher to monitor and supervise the learning offering support and scaffolding when needed. A game-based approach involves indigenous games such as morabaraba. However, before the interviews, teachers stated that they use all the teaching strategies, but this was proven otherwise during the observation. In most cases, teachers in the classroom apply the traditional method of teaching, which is known as chalk-andtalk, a method known to deny learners the opportunity to relate to mathematics.

Douglas and Isherwood [48] advises that "teaching strategies comprise interventions used by a teacher to bring about student learning". This means that learning must have occurred as a function or a correlation of the instructional operations performed by the teacher. Pedagogical practice occurs when teachers facilitate learning for diverse learners to access knowledge, activities and 
opportunities to develop skills by building on previous learning. The process begins when the learners respond to the teacher presentations and interactions and continues when the teacher facilitates the construction of new learning in a learner-centred manner. Teaching is a dynamic interaction among four components: the learner, the teacher, the curriculum, and the learned repertoire [49]. Therefore, the basic unit of pedagogy consists of the least divisible component of instruction that incorporates both learner and teacher interaction and it predicts a new stimulus of control for the learner. According to Surd et al. [50], "teaching is a complex act, and effective teaching involves a multitude of variables. Some of the variables one must consider involve children's unique learning styles, a teacher's teaching styles, physical classroom environment, community and school administration priorities and pressures". In essence, one way of motivating learners is for the teacher to outline the importance of mathematics and its relevance to their future careers.

The approach to the teaching of mathematics requires skill, insight, dedication and hard work as well as time in and time out of classroom [51]. The chalk-and-talk teaching method has been used in countries such as China with Petre [52] reporting that "Minister tells schools to copy China - and ditch trendy teaching for chalk and talk: Teachers speaking in front of a class is much more effective than independent learning". The chalk-and-talk method is believed to be effective for teaching certain topics such as number sentences and geometric patterns. However, countries such as the UK, US, Australia and New Zealand are moving away from the traditional methods of teaching to a more interactive approach that promotes collaborative teaching and learning which allows learners the freedom of learning with the teacher facilitating the process. The discovery approach is regarded as one of the effective teaching approaches specifically to assist learners to apply their prior knowledge involving their interests instead of memorising bonds, timetables and mental arithmetic. The study conducted in the UK "What Makes Great Teaching" [65] indicates that in order for learning to be effective, schools need to adapt to quality of instruction, which includes using strategies like effective questioning, the use of assessment and presenting information to students based on their preferred learning style, challenging students to identify the reason why an activity is taking place in the lesson.

The lecturing method may have positive and negative outcomes. The disadvantage of this method is that learners are individual with different learning styles and might not receive content the same way. However, lecturing method has been known to be valuable for explicit teaching which means that the teachers explains terms and it is simple way to cover the pacesetter and instruct how learning should take place. In a flipped classroom, learners are in charge of their own learning, a method that has been considered effective. According to Milman [54], the approach is gaining in popularity, particularly in mathematics classrooms, where it has been reported that it provides for greater learner motivation and interest, as well as increased learner-teacher interaction. On the other hand, the game-based learning approach is an innovative learning approach derived from the use of computer games that possess educational value or different kinds of software applications that use games for learning and education purposes such as learning support, teaching enhancement, assessment and evaluation of learners. Chien, Wu and Hsu [33] states that the $4^{\text {th }}$ Industrial Revolution (4IR) emphasises the need to use ICT in the classroom and this form of teaching assists learners in learning life skills through technology. However, this approach is not effective in remote or rural areas where learners are not familiar with ICT and are not connected to technology. Therefore, methods and approaches need to be adapted to make teaching relevant to learners in rural schools such as the introduction and use of an indigenous knowledge system.

\subsection{Indigenous Games like Morabaraba used by Teachers in the Teaching of Number Sentences and Geometric Patterns}

Before classroom observation took place, teachers stated that they embraced the prior knowledge of learners in their lesson delivery. This is in line with the NRC Statement [36], which says that teachers need to ensure that prior knowledge of learners' ability is considered to ensure effective learning. For instance, one educator mentioned that he uses chess in his class to link it to mathematical concepts. This is further supported by Ivy [38] who stated that the use of indigenous game in mathematics classroom "A game called arauru or pada, where a child balances on one foot and uses it to push a stone from one drawn rectangular box to the other help teachers in the teaching of the concepts of balancing and counting. However, the observation conducted by the researcher proved that the teacher still applied the talk-and-chalk method in his classroom. This contradicts the findings by Smith [34] when he indicated that, "good teaching is understood to involve a process of facilitating learning rather than being the simple transmission of knowledge from the educator to the learner". Teachers need to apply or implement a hands-on and interactive approach to learning activities to allow learners to develop critical thinking skills. It was evident throughout the observation period that teachers were more concerned about pace setting rather than learners' development. 
The study revealed that teachers were not familiar with using indigenous games such as morabaraba to teach mathematics concepts. However, when the concept of using indigenous games was introduced, teachers noted that geometric patterns are associated with indigenous games like morabaraba which offers the opportunity to implement alternate methods and ensure that learners work with real life situations.

\section{Conclusions and Recommendations}

Initial teachers had little idea of the use of indigenous games in the mathematics classroom to teach number sentence and geometric patterns in Grade 4 until they were introduced to them by the researchers. They later confirmed that the use of indigenous games was good for teaching number sentence and geometric geometry patterns. Furthermore, the introduction of an indigenous knowledge system would assist teachers in applying indigenous games to make the teaching and learning of number sentences and geometric patterns enjoyable and understandable to learners.

It is therefore recommended that a comprehensive study to enforce the use of morabaraba to support the teaching and learning of mathematics in both qualitative and quantitative approach should be implemented immediately to seek the opinions of respondents regarding this topic.

\section{References}

[1] H. Deresky, International management: Managing across borders and cultures: Text and cases $\left(9^{\text {th }}\right.$ Global Ed.), Pearson, Harlow, 2017.

[2] N. Flores and J. Rosa, "Undoing appropriateness: Raciolinguistic ideologies and language diversity in education", Harvard Educational Review, 85(2), 2015, pp.149-171.

[3] Department of Basic Education (DBE), CAPS Curriculum Policy Statement, Government Printers, Pretoria, 2011.

[4] R. Mudaly, "Towards decolonising a module in the pre-service science teacher education curriculum: The role of indigenous knowledge systems in creating spaces for transforming the curriculum", Journal of Education, 74, 2018, pp.47-66.

[5] M. Visser, A. Juan and N. Feza, "Home and school resources as predictors of mathematics performance in South Africa", South African Journal of Education, 35(1), 2015, pp.1-10.

[6] K. Maree and M. van der Walt, "Do mathematics learning facilitators implement metacognitive strategies?" South African Journal of Education, 27(2), 2007, pp. 223241.
[7] R.L. Molefe, Spatialising African indigenous customs in Langa (Doctoral dissertation), University of Cape Town, 2010.

[8] C. Dewah and M.M. van Wyk, "The place of indigenous cultural games by educators in the teaching and learning of mathematics", Journal of Human Ecology, 48(1), 2014, pp.189-197.

[9] N. Nkopodi and M. Mosimege, "Incorporating the indigenous game of morabaraba in the learning of mathematics", South African Journal of Education, 29(3), 2009, pp.377-392.

[10] M. Dinan-Thompson, K. Meldrum and J. Sellwood, "...it is not just a game: Connecting with Culture through Traditional Indigenous Games", American Journal of Educational Research, 2(11), 2014, pp.1015-1022.

[11] S.C. Mkwalo, The role of the department of sport and recreation in the provision and delivery of sport and recreation in KwaZulu-Natal (Doctoral dissertation), University of KwaZulu Natal, 2013.

[12] M.D.L. Mata, V. Monteiro and F. Peixoto, "Attitudes towards mathematics: Effects of individual, motivational, and social support factors", Child development research, 2012, 10pp. doi:10.1155/2012/876028

[13] B. Aronson and J. Laughter, "The theory and practice of culturally relevant education: A synthesis of research across content areas", Review of Educational Research, 86(1), 2016, pp.163-206.

[14] S.O. Bada and S. Olusegun, "Constructivism learning theory: A paradigm for teaching and learning", Journal of Research \& Method in Education, 5(6), 2015, pp.66-70.

[15] R.N. Beyers, "A five dimensional model for educating the Net generation", Journal of Educational Technology \& Society, 12(4), 2009, pp.218-227.

[16] S.Y. Fernando and F.M. Marikar, "Constructivist Teaching/Learning Theory and Participatory Teaching Methods", Journal of Curriculum and Teaching, 6(1), 2017, pp.110-122.

[17] A. Mji and M. Makgato, "Factors associated with high school learners' poor performance: a spotlight on mathematics and physical science", South African Journal of Education, 26(2), 2006, pp.253-266.

[18] J. Kriek and D. Grayson, "A holistic professional development model for South African physical science teachers", South African Journal of Education, 29(2), 2009, pp.185-203.

[19] S.A. Tachie and R. Chireshe, "High failure rate in mathematics examinations in rural senior secondary schools in Mthatha District, Eastern Cape: Learners' attributions", Studies of Tribes and Tribals, 11(1), 2013, pp.67-73.

[20] S.A. Tachie and J.M. Molepo, "Exploring Teachers' Meta-Cognitive Skills in Mathematics Classes in Selected Rural Primary Schools in Eastern Cape, South Africa", Africa Education Review, 16(2), 2019, pp.143-161. 
[21] A. Zohar, "Teachers' metacognitive knowledge and the instruction of higher order thinking", Teaching and Teacher Education, 15(4), 1999, pp.413-429.

[22] Z.R. Mevarech and B. Kramarski, "Critical maths for innovative societies: The role of metacognitive pedagogies", OECD, New York, 2014.

[23] C. Markey, D. Power and G. Booker, "Using structured games to teach early fraction concepts to students who are deaf or hard of hearing", American Annals of the Deaf, 148(3), 2003, pp.251-258.

[24] T.J. Moloi, "Using indigenous games to teach problem-solving in mathematics in rural learning ecologies", JHEA/RESA, 13(1-2), 2015, pp.21-32.

[25] M.J. Nabie and S. Sofo, "The use of games by Ghanaian teachers for teaching mathematics", Isiphetu Solwazi: Unizulu International Journal of Education, 1(2), 2009, pp.1-16.

[26] L. Grane, "Teaching the People-the Education of the Clergy and the Instruction of the People in the Danish Reformation Church." Die dänische Reformation vor ihrem internationalen Hintergrund, 1990, pp.164-184.

[27] H. Gardner, "Audiences for the theory of multiple intelligences", Teachers College Record, 106, 2004, pp.212-220.

[28] National Council of Teachers of Mathematics (NCTM) "Principles and standards for school mathematics", NCTM, 2000.

[29] National Research Council, “On evaluating curricular effectiveness: Judging the quality of $K-12$ mathematics evaluations", Washington DC, National Academies Press, 2004.

[30] J.S. Renzulli, "What makes a problem real: Stalking the illusive meaning of qualitative differences in gifted education", Gifted Child Quarterly, 26(4), 1982, pp.147156

[31] Z. Zainuddin and S.H. Halili, "Flipped classroom research and trends from different fields of study", International Review of Research in Open and Distributed Learning, 17(3), 2016, pp.313-340.

[32] G. Mphuthi, "Euclidean Geometry Workshop: Abstraction of Constructions", Association for Mathematics Education of South Africa, 2015, p11.

[33] S.P. Chien, H.K. Wu and Y.S. Hsu, "An investigation of teachers' beliefs and their use of technology based assessments", Computers in Human Behavior, 31, 2014, 198-210.

[34] P. Smith, "Preparedness for flexible delivery among vocational learners", Distance Education, 21(1), 2000, pp.29-48.

[35] Y. Copur-Gencturk, "The effects of changes in mathematical knowledge on teaching: A longitudinal study of teachers' knowledge and instruction", Journal for
Research in Mathematics Education, 46(3), 2015, pp.280330.

[36] National Research Council, "How People Learn: Brain, Mind, Experience, and School: Expanded Edition", The National Academies Press, Washington DC, 2000.

[37] A. Wildavsky, "Speaking truth to power: Art and craft of policy analysis", Routledge, London, 2017.

[38] M. Ivy, "Discourses of the vanishing: Modernity, phantasm, Japan", University of Chicago Press, Illinois, 2010.

[39] N.P. Mbusi, "An investigation into the use of traditional Xhosa dance to teach mathematics: A case study in a Grade 7 class", Doctoral dissertation, Rhodes University, 2011.

[40] P.G. Hunter, E.G. Schellenberg and U. Schimmack, U. (2010). Feelings and Perceptions of Happiness and Sadness Induced by Music: Similarities, Differences, and Mixed Emo-tions", Psychology of Aesthetics, Creativity, and the Arts, 4, 2010, 47-56.

[41] J.P Muller and J.P. Müller, "The design of intelligent agents: a layered approach", Springer Science \& Business Media Dordrecht, 1996.

[42] G.A. Almond and S. and Verba, "The civic culture: Political attitudes and democracy in five nations", Princeton University Press, New York, 2015.

[43] K. Owens, K., "Identity and Ethnomathematics Projects in Papua New Guinea", Mathematics Education Research Group of Australasia, New Guinea, 2012.

[44] R. Nabie, N. Taheri, A.M. Fard and R.F. Fouladi, "Characteristics and clinical presentations of pediatric retinoblastoma in North-western Iran", International journal of ophthalmology, 5(4), 2012, pp.510-512.

[45] R. Kumar, Research Methodology: A Step-by-Step Guide for Beginners, Sage, London, 2016.

[46] A.J. Onwuegbuzie, W.B. Dickinson, N.L. Leech and A.G. Zoran, "A qualitative framework for collecting and analyzing data in focus group research. International Journal of Qualitative Methods”, 8(3), 2009, pp.1-21.

[47] M.L. Ranney, Z.F. Meisel, E.K. Choo, A.C. Garro, C. Sasson and K. Morrow Guthrie "Interview-based qualitative research in emergency care part II: Data collection, analysis and results reporting", Academic Emergency Medicine, 22(9), 2015, pp.1103-1112.

[48] M. Douglas and B. Isherwood "The world of goods", Routledge, London, 2002.

[49] J. Harris, P. Mishra and M. Koehler, "Teachers' technological pedagogical content knowledge and learning activity types: Curriculum-based technology integration reframed", Journal of Research on Technology in Education, 41(4), 2009, pp.393-416. 
[50] V. Surd, C.M. Kantor and B.N. Pacurar, "Peripheral Cores or Central Peripheries?" Journal of Settlements and Spatial Planning, 4, 2015, p.167.

[51] J. Myerson, S. Robertson and S. Hale, "Aging and intra-individual variability in performance: Analyses of response time distributions", Journal of the Experimental Analysis of Behavior, 88(3), 2007, pp.319-337.

[52] J. Petre, "Minister tells schools to copy China - and ditch trendy teaching for chalk and talk: Teachers speaking in front of a class is much more effective than independent learning", Mail on Sunday Newspaper, 2014.

[53] R. Coe, C. Aloisi, S. Higgins and L.E. Major, "What makes great teaching? Review of the underpinning research", Sutton Trust, Durham, 2014.

[54] N.B. Milman, "The flipped classroom strategy: What is it and how can it best be used?" Distance learning, 9(3), 2012, p.85. 